\title{
La Dimensión Afectividad en la Praxis Cotidiana del Docente de Física
}

\author{
A Dimensão da Afetividade na Prática cotidiana do Professor de \\ Física
}

\section{The Affectivity Dimension in the Daily Practice of the Physics Teacher}

\author{
Jesús Ramón Briceño Barrios ${ }^{1}$ \\ Yasmelis Herminia Rivas de Briceño ${ }^{2}$ \\ Hebert Elias Lobo Sosa ${ }^{3}$
}

\begin{abstract}
Resumen
Esta investigación se propuso lograr una estructura teórica consensuada sobre el rol de la dimensión afectividad en la praxis pedagógica cotidiana del docente de Física en la construcción de saberes en la Educación Universitaria (en particular el caso Venezuela). Centrada en procesos socioculturales y orientada bajo el paradigma cualitativo, sustentado ontológica y epistemológicamente en la fenomenología y la hermenéutica. La información se obtuvo mediante entrevista en profundidad a los protagonistas, representados por profesores universitarios seleccionados con el criterio denominado bola de nieve. Los fenómenos fueron estudiados según la perspectiva de los sujetos, considerando su marco referencial, sea en el contexto donde se desenvolvieron como agentes subjetivos biográficos, como en sus múltiples contingencias experimentadas, las cuales generaron actitudes y saberes. La triangulación como contraste proporcionó credibilidad y validez al procedimiento. Surgió que la afectividad está presente en las acciones del docente, por tanto, las emociones representan elementos esenciales en la asimilación de saberes de la Física, es a través del sentir que el docente se hace ideas de la realidad e interactúa con el educando, por ello, no se pueden desligar del plano cognitivo del ser, en el proceso de enseñar contenidos de la Física. Se evidencio que la empatía, constituye el motor de las actividades en aula y una de las bases más sólidas sobre las que se fundamenta el bienestar de los docentes y la dialógica docenteestudiante, de consecuencia para comprender en toda su complejidad el acto de aprender en Física se requiere ir más allá de lo cognitivo.
\end{abstract}

Palabras clave: Dimensión afectividad, praxis didáctica, conocimientos de la Física, plano cognitivo.

\section{Resumo}

Esta pesquisa objetivou alcançar uma estrutura teórica consensual sobre o papel da dimensão afetividade na prática pedagógica cotidiana do professor de Física na construção do conhecimento na Educação Universitária (em especial o caso da Venezuela). Focado em processos socioculturais e pautado pelo paradigma qualitativo, apoiado ontologicamente e epistemologicamente em fenomenologia e hermenêutica. As informações foram obtidas por meio de entrevista em profundidade com os protagonistas, representados por professores universitários selecionados com o critério denominado snowball. Os fenômenos foram estudados segundo a perspectiva dos sujeitos, considerando seu referencial referencial, seja no contexto em que se desenvolveram como agentes biográficos subjetivos, seja nas suas múltiplas contingências vivenciadas, que geraram atitudes e conhecimentos. A triangulação como contraste forneceu credibilidade e validade ao procedimento. Verificou-se que a afetividade está presente nas ações do professor, pois, as emoções representam elementos essenciais na assimilação do conhecimento da física, é através do sentimento de que o professor faz ideias de realidade e interage com o aprendiz, Isso não pode ser separado do plano cognitivo do ser, no processo de ensino de conteúdos da Física. Evidenciou-se que a empatia é o motor das atividades de sala de aula e um dos fundamentos

\footnotetext{
${ }^{1}$ Doctor en Educación UFT, Venezuela; Professor visitante, IMEF-Instituto de Matemática, Estatística e Física - Mestrado Profissional em Ensino de Física (MNPEF). Universidade Federal de Rio Grande - Brasil. jesusrbb@gmail.com.

${ }^{2}$ Doctora en Educación, UFT, Venezuela; CRINCEF-Centro Regional de Investigaciones en Ciencias, su Enseñanza y Filosofía - ULA-NURR,Venezuela.

${ }^{3}$ Doctor en Educación ULA, Venezuela; CIEFI - Comunidade de Indagação em Ensino de Física Interdisciplinar - FURG; IE - Instituto de Educação - Programa de Pós-graduação em Ciências: Química da Vida e Saúde (PPGEC). Universidade Federal de Rio Grande - Brasil helobos.brasil@gmail.com
} 
mais sólidos sobre os quais se baseia o bem-estar dos professores e o diálogo professor-aluno, como consequência de compreender em toda sua complexidade o ato de aprender na física é necessário ir além do cognitive.

Palavras-chave: dimensão afetiva, práxis didática, conhecimento da física, plano cognitivo.

\begin{abstract}
This research aimed to reach a theoretical consensus structure on the incidence of the affectivity dimension in the dialogic of the Physics teacher in his pedagogical praxis in the construction of knowledge in Venezuelan University Education. Focused on sociocultural processes and oriented under the qualitative paradigm, supported ontologically and epistemologically in phenomenology and hermeneutics. The information was obtained by means of an in-depth interview with the protagonists, represented by university professors selected with the criterion denominated snowball. The phenomena were studied according to the perspective of the subjects, considering their frame of reference, either in the context where they developed as subjective biographical agents, as in their many experienced contingencies, which generated attitudes and knowledge. On the other hand, the triangulation as a contrast provided credibility and validity to the procedure. It emerged that affectivity is present in the actions of the teacher, therefore the emotions represent essential elements in the assimilation of knowledge of physics, it is through the feeling that the teacher makes ideas of reality and interacts with the student, therefore, Cannot be disconnected from the cognitive plane of being, in the process of teaching contents of physics. It was also shown that empathy is the engine of classroom activities and one of the most solid foundations on which teachers' well-being and teacher-student dialogues are based. This is a consequence of understanding in all its complexity the act of Learning in physics requires going beyond the cognitive
\end{abstract}

Keywords: Dimension of affectivity, didactic practice, knowledge of Physics, cognitive plane.

\title{
1. Introducción
}

La situación que vive actualmente la sociedad no requiere grandes reflexiones para contrastar que se mueve orientada mediante coordenadas existenciales poco halagadoras y muy preocupantes. La revolución tecnológica y los continuos y acelerados cambios que ha provocado, además de la irrupción de la era de la información, que ha alterado los principios mismos en que el colectivo fundaba su accionar, produciéndose el fenómeno de la globalización, el neoliberalismo exacerbado y el dualismo social, exaltándose además, la especulación de tipo financiero y el consumismo exagerado, lo que de alguna manera ha coadyuvado a conformar un panorama con una visión de pinceladas, donde destacan sustancialmente las expresiones de lo que se ha denominado crisis.

Crisis de identidad, de valores, generacional, económica, educativa y en el ámbito de la misma, crisis en el estudio de carreras de carácter científico. En el marco de esta situación conflictiva, no obstante, la sociedad vuelca nuevamente sus ojos hacia la educación como opción benefactora. Al respecto se debe tener en consideración lo expresado por Alonso y Loza (2012) en relación a la significación de la educación vinculada al contexto de la sociedad, de manera muy reciente, quienes han manifestado que en el transcurso de la historia y en su particularidad de evolución oscilante, se pasó del optimismo pedagógico de los años sesenta y setenta sustentado en el idealismo ingenuo relacionado con el poder transformador 
de la educación, al pesimismo educativo vigente basado en el determinismo que lo único que puede concebir la educación es la transcripción de las desigualdades sociales.

Esto conduce a tener que esbozar una nueva perspectiva, surgiendo como tal la comunicativa, con una visión de lo comunicativo que genere interacciones, solidaridades y acuerdos entre la diversidad de sujetos que intervienen en el proceso, ya que la enseñanza es un proceso de comunicación que comprende: información, estimulación al descubrimiento, despertar el interés, feed-back, formación de capacidades, modelación de actitudes y climatización afectiva, además de varios ciclos sucesivos de profundización y maduración (Titone, citado por Navarro 2011).

Asimismo se requiere visualizar una metodología de enseñanza aprendizaje, en este caso la dialógica, sustentada en el aprendizaje dialógico que aporta una concepción diferente del proceso enseñanza-aprendizaje en el que para aprender, se precisa de circunstancias de interacción entre las personas, donde además el diálogo que se establezca entre las partes tiene que estar fundamentado en una relación de igualdad, ausente de situaciones de poder, lo que implica que todos y todas tienen conocimiento que aportar, reconociendo así, la inteligencia cultural en todas las personas (Gómez, Girones, Gil, Catala, Bacete y Aparicio, 2014).

En relación a lo expresado Freire (1997), sostiene que la dialogicidad es una condición imprescindible para el conocimiento. El diálogo constituye un instrumento para organizar dicho conocimiento y conlleva una postura crítica y una preocupación por aprehender las consideraciones que median entre los actores involucrados; representando estos aspectos los elementos que constituyen fundamentalmente la esencia epistemológica que promueve la construcción del conocimiento. Es de precisar que la metodología dialógica referida, debe con su accionar predominar sobre el ingenuo idealismo transformador convirtiéndola en algo factible que favorezca la transformación social solidaria y prevalezca sobre la visión fatalista de la educación reproductora de desigualdades sociales.

En relación al término educación de acuerdo a lo reportado por Pozo, Álvares, Luengo y Otero (2004), tiene un doble origen etimológico, por una parte, el verbo latino educere significa conducir fuera de, extraer de dentro hacia fuera, desde esta concepción, la educación se entiende como el desarrollo de las potencialidades del sujeto basado en la capacidad que tiene para desarrollarse. Más que la reproducción social, este enfoque plantea la configuración de un sujeto individual y único. Por otra parte, el verbo educare, el cual se identifica con los significados de criar, alimentar y se relaciona con las influencias educativas o acciones que desde el exterior se llevan a cabo para formar, criar, instruir o guiar al 
individuo. Se refiere por tanto a las relaciones que se establecen con el ambiente que son capaces de potenciar las posibilidades educativas del sujeto.

Si bien, en determinados momentos históricos, ambas posiciones, individualización y socialización, por separado, han sido esgrimidas para fundamentar los procesos educativos, actualmente se mira a la complementariedad, concibiéndose la educación como el conjunto de influencias externas (socialización, educatividad) que permiten el desarrollo de las potencialidades internas del sujeto (individualización, educabilidad). En esta última interpretación se manifiestan Durkheim y Santacana entre otros (citados por Luengo, 2011), al sugerir que el proceso educativo debe estar enmarcado en lo individual y lo social.

Al este sentido cabe señalar que la educación es sustancialmente transformación solidaria del medio (en su disposición sustentable y sostenible) y de la persona. Es una transformación de todo ser humano en beneficio de la vida en sentido comunitario, para el buen vivir de todas y todos los ciudadanos en libertad y autonomía, sin discriminación. Para tal fin, se requiere que el aprendizaje sea significativo. En razón de lo cual se debe considerar que la construcción de significados no es algo individual, sino algo que se realiza de manera colectiva e interactiva, en relación con los demás y dentro de una comunidad, es decir, para que el aprendizaje se pueda catalogar como tal, debe estar abierto al intercambio entre las partes.

Ahora bien, el diálogo desde la perspectiva pedagógica según lo expresado por Burbules (1999), representa un intercambio continuo, comunicativo y evolutivo por medio del cual se logra una aprehensión más plena del mundo, de la propia subjetividad y de los demás. Desde esta perspectiva el diálogo es una actividad dirigida al descubrimiento y a una comprensión nueva que mejora el conocimiento de los que toman parte en él. Sin embargo de acuerdo a las vivencias de los autores de este trabajo y las observaciones realizadas a lo largo de sus carreras como docentes, el dialogo por lo general, en este contexto, sufre de ubicuidad aparente, en cuanto se da por descontado que la interacción en el aula es de carácter dialógico, donde los estudiantes están en constante intercambio con el docente como facilitador y promotor de los procesos del pensamiento como surgidores de conocimiento, sin embargo existen elementos que llevan a señalar que eso es cuestionable, y que se trata de un enfoque idealizado de la relación estudiante-profesor en el aula.

Por tanto, a fin de lograr una dialógica, con verdaderos intercambios de pensamientos e ideas se requiere el respeto mutuo de los participantes en el dialogo de manera íntegra, sin denigrar de ninguna de las partes que conforman el ser, ni tampoco soslayar ninguna de ellas, considerando que tanto la parte afectiva como la cognitiva con sus respectivos elementos 
constitutivos que las hacen posibles, forman parte del mismo ser e interactúan entre sí, para al final configurar las maneras de pensar, sentir, hacer y crear conocimiento en el ser humano. Ello representa el gran reto para el docente y particularmente para el docente de Física, quien debe abordar la docencia como la situación en la que el conocimiento es co-construido por él y el estudiante de manera colaborativa en actividades conjuntas y en la aceptación del uno y del otro de manera armónica y dialógica, esto lo conduce a reflexionar sobre su dinámica emocional en su praxis educativa del día a día en las interacciones en aula y fuera de ella, teniendo que adentrarse en sus consideraciones más allá de lo meramente cognitivo.

Los hallazgos de estas reflexiones expresadas a través de las entrevistas en profundidad, constituyeron los elementos que posibilitaron la construcción de un corpus teórico, que surgió de analizar hermenéuticamente a través de la dialéctica interpretativa la realidad de los actores sociales involucrados, es decir de los profesores universitarios de Física, esto se logró haciendo comparaciones y estableciendo analogías que representaban conceptualmente las realidades consideradas.

\section{Acercamiento al Objeto de Estudio}

Visualizar, de manera retrospectiva los acontecimientos, ocurridos en los últimos tiempos, permite apreciar que tales sucesos se han caracterizado por una serie de cambios profundos y acelerados de conocimiento y avances tecnológicos sin precedentes en la historia de la humanidad, con mención muy particular y especial al vertiginoso desarrollo de las tecnologías de información y comunicación (TIC) y las redes sociales concernientes a ellas. Esto ha comportado una exigencia cada vez mayor en cada uno de quienes les ha tocado vivir estos tiempos, para asimilar en parte los diversos elementos asociados a esas transformaciones y no quedarse rezagados en áreas que se han vuelto vitales en el desenvolvimiento como profesionales y en especial a quienes se desempeñan en el área educativa, involucrando inclusive el campo de sus relaciones personales.

Los requerimientos en el campo de trabajo son cada día más marcados, lo que demanda de expertos competentes que den respuesta a los problemas de una realidad compleja y dinámica. Donde sobre sale además que la incertidumbre forma parte de la cotidianidad; demandando por tanto de quienes se dediquen a esta exigente actividad que adopten en su trabajo, una actitud reflexiva y crítica con respecto a la realidad educativa y que posean capacidades personales, técnicas y profesionales para investigar científicamente ese escenario y transformarlo creativamente. 
Para ello se necesitan personas que asuman el reto como pensadores, tal como sostiene Freire (1996), que "realicen la tarea permanente de estructurar la realidad, de preguntarle y preguntarse sobre lo cotidiano y evidente, tarea ineludible para todo trabajador social". (p. 123). Lo que de alguna manera evidencia que los especialistas dedicados a la formación del futuro ciudadano, entre ellos los conocedores de la educación, deben comprometerse como investigadores de su propia práctica pedagógica y reflexionar críticamente acerca de la misma para mejorarla, a través del contraste, el diálogo, el debate, la deliberación y la experiencia compartida sobre las vivencias pedagógicas habituales y los paradigmas donde se enmarcan.

Por otra parte la identidad del docente de Física según Madera (2008), se construye y reconstruye a partir de necesidades, de prácticas y de problemas detectados en las interacciones con el entorno natural y social que tiene lugar en el entramado contexto, fenomenológico natural, sociocultural particular, histórico, ideológico e institucional en que está inmerso, algo que en mayor o menor medida se da también en los educadores de las otras especialidades del conocimiento, pero con las particularidades para cada uno de los casos. Ahora bien, es a través de estas interacciones que se van aprendiendo los conocimientos teóricos y prácticos conducentes a la toma de decisiones sobre qué aspectos de la Física a enseñar, sobre cómo enseñar y sobre qué y cómo evaluar.

También destaca que tradicionalmente en los procesos de formación se ha contemplado de forma explícita el desarrollo de competencias relacionadas con el saber y el saber hacer racional, pero en cambio no se tienen para nada en cuenta el desarrollo de las competencias de la dimensión afectiva. En este sentido y de acuerdo a lo expresado por Rubia (2007), se ha dejado de lado que el ser humano es un ser emocional además de racional, y que debido al papel que las emociones juegan en la conducta, el organismo se fía más de ellas que de la razón, por lo que son causantes de la mayoría de los comportamientos.

De igual manera, según lo expresado por Levy (2000), se podría decir de forma general, que en su búsqueda de identidad, el docente requiere primordialmente conocerse a sí mismo en el campo emocional, pero a este conocimiento se llega mediante las interacciones con los estudiantes, familias y colegas, en tanto que, esa es una construcción social e individual, mediante la cual se aprende a establecer relaciones entre sus propias emociones y la de sus estudiantes, ya que estos vínculos son los que le permiten encontrar satisfacción en su trabajo, condición imprescindible para una enseñanza eficaz y significativa.

En razón de lo referido precedentemente, el docente en este campo del conocimiento, tradicionalmente considerado árido, difícil y complicado según lo señalado por Briceño y otros (2009); debe emprender el proceso de enseñanza, desde un enfoque holístico y complejo 
que integre de forma armónica los aspectos científicos de la Física, así como los aspectos pedagógicos, epistemológicos y ontológicos involucrados en el acto educativo y que además armonice de forma coherente la teorización con la práctica de la enseñanza, considerando la formación integral del ser con sus diversas manifestaciones interactuantes y complementarias. Tendría, además, la necesidad de considerar que el trabajo en la enseñanza de acuerdo a lo manifestado por Briceño et al (2011), está basado principalmente en las relaciones interpersonales con los estudiantes y con otros compañeros, por lo que las vivencias emocionales son permanentes y modulan la relación docente-estudiante.

A las consideraciones precedentes habría que agregar algunas inquietudes y apreciaciones captadas como comentarios de algunas conversaciones informales con directores de algunas Instituciones Educativas, entre profesores de Física y de otras especialidades así como también entre los mismos estudiantes: un director se expresaba de sus profesores de Física de la manera siguiente: "sería tan bueno para los estudiantes que los profesores, fuesen más accesibles, menos distanciados... en fin más humanos y con sentimiento".

Respecto a los comentarios entre profesores y estudiante se tiene "esos carajos de Física son tan pedantes se creen únicos " y "se creen dioses enclaustrados en su trono a quienes hay que rendirles pleitesía por su saber", además "la racionalidad es adecuada si se combina con un toque de afecto pues a esa receta como que le falta sazón", "comprender la Física no es algo que puedan hacer todos así que no pierdan su tiempo dedíquense a otra cosa", también "tengo 70 ... en un curso pero apenas aplique la primera evaluación mando de paseo más de la mitad y así se emparejan las cosas". Estas inquietudes conducen a plantear las interrogantes de la investigación, las cuales se mencionan seguidamente:

¿Cuáles son las condiciones del estado del arte de la dialógica emocional del docente de Física en su praxis pedagógica cotidiana en el contexto de la Educación Universitaria?

¿Qué significados otorgan los docentes de Física a la dialógica emocional en su praxis pedagógica en el contexto de la "Educación Universitaria"?

¿De qué manera se podrá elaborar una aproximación teórica acerca de la dialógica emocional del docente de Física en su praxis pedagógica en el contexto de la Educación Universitaria?

Para responder las interrogantes el recorrido investigativo se orientó con los propósitos siguientes:

a) Pretensión General 
Generar una estructura teórica consensuada acerca del rol de dimensión afectividad del docente de Física en su praxis pedagógica en la construcción de saberes en la Educación Universitaria (caso Venezuela).

\section{b) Pretensiones Específicas}

1. Reconstruir el estado del arte de la dialógica de la dimensión afectividad del docente de Física en su praxis cotidiana en la construcción de saberes a nivel Universitario.

2. Conocer los significados que le otorgan los docentes de Física a la dimensión afectividad en su praxis pedagógica en la construcción de saberes dentro del contexto de la Educación Universitaria.

3. Elaborar una aproximación teórica acerca de la dimensión afectividad del docente de Física en su praxis pedagógica en la construcción de saberes dentro del contexto de la Educación Universitaria.

\section{Referentes Teóricos}

En este trabajo se intentó aproximarse a las concepciones de los actores sociales (profesores del área de Física en el contexto Universitario) en torno a la dimensión afectividad y su relación con la pedagogía en el acto educativo en la construcción de saberes. Para lograr lo planteado se confecciono un basamento teórico que la sustento, para lo cual se requirió aclarar lo siguiente:

En lo referente al término praxis pedagógica Díaz, Martínez, Roa, y Sanhueza (2010), detallan que en cada aula ocurren eventos que permiten desarrollar, una comprensión más profunda del proceso enseñanza-aprendizaje, ya que esa representa un escenario en el que interactúan una serie de variables didácticas que hacen de dicho proceso un acto complejo. Los docentes se relacionan con los estudiantes, los objetivos, los métodos, las actividades, los materiales, la evaluación y el contexto. Sin embargo, un acercamiento a la comprensión de dicha complejidad se puede lograr al abordar las creencias, las emociones y las actuaciones docentes para interpretar la multitud de variables que ocurren en él fenómeno de la construcción y transmisión de saberes.

La idea de explorar la acción didáctica desde esta perspectiva, se relaciona con la alta cuota de subjetividad y complejidad que dicho fenómeno reviste. La actuación del docente y su concepción del proceso de enseñanza y aprendizaje, se puede comprender al entrar al entramado de elementos que sostienen su praxis pedagógica. Al respecto, cabe destacar que investigaciones vigentes en el campo de la neurociencia realizadas por Damasio (2010), han puesto de manifiesto que los aspectos afectivos, se encuentran intrínsecamente relacionados 
con el pensamiento, la comprensión y los procesos conscientes de metacognición y autorregulación involucrados en el aprendizaje. Igualmente, estudios realizados en el ámbito psicopedagógico, donde destacan, los aportes de Sheehtman y Leiehtenritt (citados por García, 2009), han puesto de manifiesto que lo que se ha considerado como enseñanza afectiva, tiene un impacto positivo sobre el crecimiento personal de los estudiantes, sobre el aprendizaje y los procesos de socialización.

Ahora bien, la enseñanza está vinculada a la praxis pedagógica, la cual representa la serie de actos conscientes o no, propios y ajenos, donde se ponen en juego, los conocimientos académicos, las experiencias, las rutinas y creencias para constituirse en un saber que educa en un contexto político, social y ético. La cual compromete momento a momento a los diferentes actores que intervienen en el escenario educativo. De acuerdo a lo expresado por Foliari (2005), la praxis está influenciada por las concepciones de los actores sociales vinculados a la misma, sobre el mundo, la ciencia, la educación y tantas otras concepciones, las cuales actúan como instrumentos que sirven para interpretar la realidad, en este caso la realidad desde la visión de la enseñanza de la Física, lo que permite configurar los respectivos modelos didácticos para dilucidarla.

En relación a los modelos mencionados, esos deben tener en consideración las diversas teorías que sobre el aprendizaje han sido elaboradas, especialmente las que tienen vigencia actualmente y tienen que ver según Piaget (1969), con la construcción del conocimiento, es decir, con el aprendizaje constructivista ya que las actividades que el estudiante efectúa tienen como propósito construir el conocimiento; representa una construcción personal de la realidad en la que el sujeto reestructura los contenidos informativos que recibe en el contexto de la instrucción, resaltándose así mismo, la idea que hay muchas maneras de aprender, que todos los alumnos son diferentes y que esas diferencias no se limitan a las condiciones, intelectuales, sino que abarcan, sobre todo las diferencias, afectivas y culturales.

Por tanto, no se debe obligar a los alumnos a realizar construcciones homogéneas en el aprendizaje, más sí a negociarlas desde una configuración comunitaria. El aprendizaje será experiencial, o no será aprendizaje y debe comenzar según Ausubel (1991) por un estado de motivación o sensibilización y culminar con la comprobación del nivel de progreso alcanzado. Además, eso funcionará mejor si se da en contextos reales y no en condiciones artificiales o alejadas de la vida, como sucede habitualmente en las Instituciones Educativas.

Debe también considerar la autorregulación. Donde lo normal según Vygotsky (1978) es que el aprendizaje sea dirigido, al principio, por el profesor, puesto que es el que sabe lo 
que hay que aprender y cómo hay que aprenderlo. Es lo que denomina un aprendizaje fundamentado en el heterocontrol. Pero, en la medida que el aprendizaje, adelanta, el profesor tiene que transferir al alumno la dirección de ese aprendizaje. Es en este momento que se pasa del heterocontrol al autocontrol, es decir, al aprendizaje autorregulado.

Ya que, como lo han señalado los expertos, a decir de Perkins (citado por Gaviria, Gómez y Patiño, 2012), lo más importante del aprendizaje no es lo que se asimila en sí mismo, sino el aprender a aprender, lo que se logra solo cuando el alumno es capaz de regular el proceso de adquisición de conocimiento de manera independiente.

\section{Dialógica emocional}

La Real Academia Española (RAE, 2001) considera el término dialógica, como relativo al diálogo, que presenta forma dialogada, o que contempla y propicia la posibilidad de discusión. En ese sentido se tiene que en la sociedad actual, denominada de la información, la comunicación representa una de sus características principales, con un significado amplio en el que se incluye el diálogo desde la aceptación del otro en condiciones de igualdad, se considera su transcendencia más allá de los espacios físicos, dando paso a la posibilidad de generarse con la mediación de herramientas tecnológicas, y se valora como un proceso que debe impulsar la reflexión crítica en comunidad. Al respecto Elboj y Gómez (2009), al referirse a este aspecto, señalan que en esta sociedad, cada vez más, existen personas y grupos que tratan de resolver sus diferencias y encontrar consensos mediante la disertación, lo que implica que hagan así, no solo más realidades comunicativas sino, propósitos más precisos.

Se evidencia que el diálogo constituye un elemento sumamente importante en los procesos de formación actual que aluden a la necesidad de un individuo más humano, capaz de resolver conflictos, construir socialmente el conocimiento, potenciar sus habilidades para el aprovechamiento de la información y protagonizar las transformaciones culturales, sociales y económicas partiendo de la reflexión crítica en comunidad de su realidad.

Así también Varas (2007), lo asume como parte fundamental de la comunicación, concibiéndolo como ".... una actividad dialéctica, intersubjetiva, en cuyo desarrollo el lenguaje se manifiesta como la capacidad exclusivamente humana que acerca y suscita emociones y sentimientos" (p. 101).

En este orden de ideas, algunos de los exponentes que se ubican en las tendencias comunicativas donde enfatizan el valor del diálogo y el lenguaje en la acción educativa son, entre otros: Freire (1973) con su perspectiva dialógica de la pedagogía, Habermas (1987) con su teoría de la acción comunicativa, Varas (ob cit) con su teoría dialógica de la educación, Vygotsky (ob cit) desde la visión comunicativa del enfoque del constructivismo histórico 
social y Flecha (2006) con los principios de la teoría del aprendizaje dialógico en la sociedad de la información.

Mención especial para Maturana y Bloch (1998) con su "dialogo emocionar" (p. 43) y su "melodía emocional" (p. 46), ya que según lo afirmado por los autores "...el $90 \%$ de la comunicación humana se da mediante un lenguaje no verbal que involucra gestos y emociones" (p. 94). Por último y dado que el amor y la ternura son ciertos tipos de emociones que procesadas por el cerebro del ser humano se han transformado en sentimientos, no se pueden obviar las ideas propuestas por Pérez (2011) sobre la pedagogía del amor y la ternura.

\section{Recorrido Metodológico de la investigación}

La metodología, por definición, es la vía, forma o manera que orienta las acciones y los pasos que se han de seguir en el proceso de investigación para lograr un conocimiento preciso y seguro, para la obtención de resultados confiables. Desde esta definición, se describe y se argumenta el enfoque cuya orientación consiente abordar la teorización y la praxis o aplicación de la investigación que se pretendió llevar a efecto.

Al respecto se señala que esta investigación se centró en procesos socioculturales con enfoques provenientes de la psicología cognitiva, lo que aunado a los propósitos trazados en ella llevo a deliberar que la misma se cobijase en el paradigma de la investigación cualitativa y los actores sociales involucrados en ella fueron seleccionados entre el grupo de profesores del área de Física del Núcleo Universitario Rafael Rangel de la Universidad de los Andes (NURR-ULA) y del Pedagógico de Maracay, quienes al momento de la realización de la investigación se encontraban dictando en conjunto, los cursos de la maestría en educación mención enseñanza de la Física en las mencionadas Instituciones .

Para dicha elección se tomó en cuenta: los años de servicio, formación académica y trayectoria productiva en lo académico en cuanto a la práctica pedagógica del área de especialidad. Esa selección de informantes clave tuvo en consideración que la investigación de corte cualitativo según lo expresado por Glaser y Strauss (1967), debe ser flexible en su diseño y no debería conocerse a priori ni el número ni el tipo de informantes, eso debería ser más bien el fruto del propio proceso generado con el acceso al campo del investigador.

Como criterio de selección se usó la bola de nieve, el cual de acuerdo a la descripción de Cohén y Manión (1990) es un procedimiento que supone que el investigador identifique a un pequeño grupo de individuos que tienen las características que se requieren. Estos a su vez operan como informantes para identificar a otros que califican por inclusión, los cuales a su vez identifican a otros más. El proceso termina cuando se agota la lista de personas sugeridas. 
Este procedimiento condujo a la final de manera oportuna y en base a las ideas expresadas a considerar la elección de tres (3) informantes clave. Estos, de acuerdo a los criterios que orientaron la investigación suministraron la información necesaria para interpretar y dar una aproximación de la realidad del fenómeno investigado que correspondió a la incidencia de la dimensión afectiva del docente de Física en su praxis educativa.

Se optó por un posicionamiento epistemológico interpretativista, por tanto la realidad empírica debió ser interpretada en los términos dilucidados por los sujetos observados. $\mathrm{Al}$ aceptar este significado creado intersubjetivamente como una parte integral del sujeto, el investigador debió recoger la información que describía tanto los datos, como los hechos objetivos que daban significado a los aspectos subjetivos que desencadenan el comportamiento. De esta manera, el enfoque considerado para éste estudio permitió interpretar, a partir de la interacción con los actores sociales estudiados y de la interpretación subjetiva entre el investigador y los investigados, sus experiencias vividas, los comportamientos, percepciones y emociones, así como sus concepciones acerca del funcionamiento organizacional, los significados sociales, los modelos culturales y la interacción entre los fenómenos.

Por otra parte, se consideró de suma importancia la utilización del procedimiento de la triangulación en esta búsqueda ya que permitió reinterpretar la situación en estudio, a la luz de evidencias provenientes de las fuentes obtenidas mediante la técnica de la entrevista. La triangulación como procedimiento de contraste contribuyó a lograr la credibilidad y validez del estudio entre los aspectos teóricos, los resultados de campo y la interpretación de ambos.

\section{Instrumentos para la obtención de información recogida y su tratamiento}

De acuerdo al contenido subjetivo involucrado en el proceso, se consideró oportuno para la recogida de la información usar la entrevista en profundidad y las observaciones de campo. Después de haber realizado cada una de las entrevistas consideradas, y de haber recogida la información proporcionada por los diversos actores, se procedió con el amplio proceso de la categorización.

En esta fase, se recurrió a la reflexión y el análisis en profundidad, mediante un proceso recursivo donde se leyó y releyó lo narrado, de esta manera se eligieron las subcategorías emergentes más apreciables y adecuadas a lo que representaban las pretensiones metodológicas de la investigación. Así surgieron cinco (5) categorías que fueron articuladas entre sí, y colocadas de forma tal que la lectura interpretativa se realizase de manera flexible y recursiva, donde cada una de ellas integró aspectos apreciables que responden al objeto de estudio de la investigación y que estaban directamente relacionados con las vivencias de los 
informantes. La caracterización fue la siguiente:

Categoría: Reminiscencias. Esta categoría incorpora los diversos aspectos o experiencias en el contexto familiar, así como de las relaciones con las personas que los informantes vivenciaron en el entorno donde se desenvolvieron. Estos momentos permiten crear en el ser el sentimiento de vínculo o pertenencia familiar de acuerdo al cual se arraiga profundamente en el interior de cada uno, al punto que resulta básico en la construcción de la personalidad del individuo.

Categoría: Formación recibida. Se relaciona con todas las experiencias personales o vivencias de los actores sociales que de una u otra manera contribuyeron con su formación y favorecieron la creación de la red de significados denominada sapiencia de la Física.

Categoría: Concepciones del día a día. Involucra todas aquellas acciones y rutinas comportamentales relacionadas con el diario hacer de los actores sociales, donde se manifiesta la capacidad comunicativa de los participantes en el acto de comunicar, para compartir los contenidos culturales y curriculares, porque su fin es contemporáneamente la enseñanza y el aprendizaje de la Física.

Categoría: Expresando emociones en la construcción de saberes. Comprende el conjunto de situaciones en las cuales se vieron envueltos los actores sociales que de alguna manera reflejan la expresión de una dimensión afectiva incluyendo los sentimientos de los entrevistados en el proceso de construcción de saberes en Física.

Categoría: Visualizando la dialógica emocional en el docente de física. Incluye la serie de circunstancias vividas por los docentes en el desarrollo del acto educativo que involucran el surgir de emociones, dentro y fuera del contexto del aula, estas además permiten enfatizar la dialógica afectiva que se manifiesta en el proceso comunicativo entre el docente y los estudiantes.

\section{Develando lo Narrado}

En este momento de la investigación se pretendió aproximar la interpretación de la realidad relatada por los informantes, una tentativa por apreciar el pensamiento interior de cada uno de ellos, y desde esta perspectiva, expresarlo haciendo uso de la palabra escrita que dejará testimonio para la posteridad. Eso representó un intenso y difícil trabajo, en el cual la palabra, a través de sus enunciados, abrió un abanico de ideas, intuiciones e inferencias. Las categorías y sus correspondientes subcategorías, fueron organizadas en la siguiente tabla.

Tabla 1 Articulación de la información del actor social 1 
RELACult - Revista Latino-Americana de Estudos em Cultura e Sociedade

\begin{tabular}{|c|c|}
\hline Categoría & Subcategoría Informante 1 \\
\hline \multirow{3}{*}{ Reminiscencia } & $\checkmark \quad$ Infancia con una niñez tranquila \\
\hline & $\checkmark \quad$ Lo importante de compartir \\
\hline & $\checkmark \quad$ Las muchachas eran más recatadas \\
\hline \multirow{3}{*}{ Formación recibida } & $\checkmark \quad$ Una estrategia de enseñanza \\
\hline & $\checkmark \quad$ La fuerza del amor \\
\hline & $\checkmark \quad$ Elementos que uno sabe y reconoce que afectan el aprendizaje y la enseñanza \\
\hline \multirow{6}{*}{$\begin{array}{l}\text { Concepciones } \\
\text { del día a día }\end{array}$} & $\checkmark \quad$ He logrado estimular algunos estudiantes para que participen \\
\hline & $\checkmark \quad$ Intentando incentivar a los estudiantes \\
\hline & $\checkmark \quad$ Los resultados no eran los esperados \\
\hline & $\checkmark \quad$ En el papel de profesor \\
\hline & $\checkmark \quad$ La práctica pedagógica \\
\hline & $\checkmark \quad$ Sentirse un poco hijo del profesor \\
\hline \multirow{6}{*}{$\begin{array}{l}\text { Expresando } \\
\text { emociones en } \\
\text { construcción } \\
\text { saberes }\end{array}$} & $\checkmark \quad$ La afectividad \\
\hline & $\checkmark \quad$ Predisposición natural \\
\hline & $\checkmark \quad$ Nos gustaba también enseñar \\
\hline & $\checkmark \quad$ Continuamos motivados a procurar enseñar \\
\hline & $\checkmark \quad$ Genera profundas emociones, pudiéramos decir, afectos y sentimientos \\
\hline & $\checkmark \quad$ Actitudes asumidas \\
\hline \multirow{7}{*}{$\begin{array}{l}\text { Visualizando la } \\
\text { dialógica } \\
\text { emocional en el } \\
\text { docente de física }\end{array}$} & $\checkmark \quad$ La emotividad \\
\hline & $\checkmark \quad$ Situaciones vividas \\
\hline & $\checkmark \quad$ Duros con los estudiantes \\
\hline & $\checkmark \quad$ Lograba motivarnos \\
\hline & $\checkmark \quad$ Sentimientos de afecto entre ese egresado y nosotros \\
\hline & $\checkmark \quad$ No logra que todos tengan el mismo grado de afectividad \\
\hline & $\checkmark \quad$ Es importante generar buenas emociones \\
\hline
\end{tabular}

Tabla 2 Articulación de la información del actor social 2

\begin{tabular}{llll}
\hline Categoría & & \multicolumn{2}{c}{ Subcategoría Informante 2} \\
\hline \multirow{2}{*}{ Reminiscencia } & $\checkmark$ & Tuve una infancia muy bonita \\
& $\checkmark$ & Éramos muy unidos \\
& $\checkmark$ & Te voy a ayudar \\
\hline \multirow{3}{*}{ Formación recibida } & $\checkmark$ & No nos regañaba porque salíamos mal \\
& $\checkmark$ & Me faje a estudiar \\
& $\checkmark$ & Cosas que aprendí, que aquí no hubiera aprendido \\
Concepciones & $\checkmark$ & No tenía en mente otra cosa \\
& $\checkmark$ & Me gustó tanto \\
& $\checkmark$ & Lograr cierta afinidad o amor \\
& $\checkmark$ & No consideran la importancia que la afectividad tiene \\
& $\checkmark$ & Manejar la emocionalidad \\
\hline
\end{tabular}


RELACult - Revista Latino-Americana de Estudos em Cultura e Sociedade

\begin{tabular}{|c|c|c|}
\hline & $\checkmark$ & Uno quisiera que aprobaran todos \\
\hline \multirow{6}{*}{$\begin{array}{l}\text { Expresando } \\
\text { emociones en } \\
\text { construcción } \\
\text { saberes }\end{array}$} & $\checkmark$ & El proceso afectivo \\
\hline & $\checkmark$ & Siempre me ha gustado estudiar \\
\hline & $\checkmark$ & Comienzo amar la física \\
\hline & $\checkmark$ & Angustiado y muy preocupado \\
\hline & $\checkmark$ & Una prueba en blanco es un fracaso del estudiante pero también del profesor \\
\hline & $\checkmark$ & La parte emotiva \\
\hline \multirow{7}{*}{$\begin{array}{l}\text { Visualizando la } \\
\text { dialógica emocional } \\
\text { en el docente de } \\
\text { física }\end{array}$} & $\checkmark$ & Entregarse íntegramente \\
\hline & $\checkmark$ & Un alto contenido de afectividad \\
\hline & $\checkmark$ & Las satisfacciones \\
\hline & $\checkmark$ & Muy impulsivo \\
\hline & $\checkmark$ & Están interesados \\
\hline & $\checkmark$ & Le tenían temor \\
\hline & $\checkmark$ & Componente emocional \\
\hline
\end{tabular}

Tabla 3 Articulación de la información del actor social 3

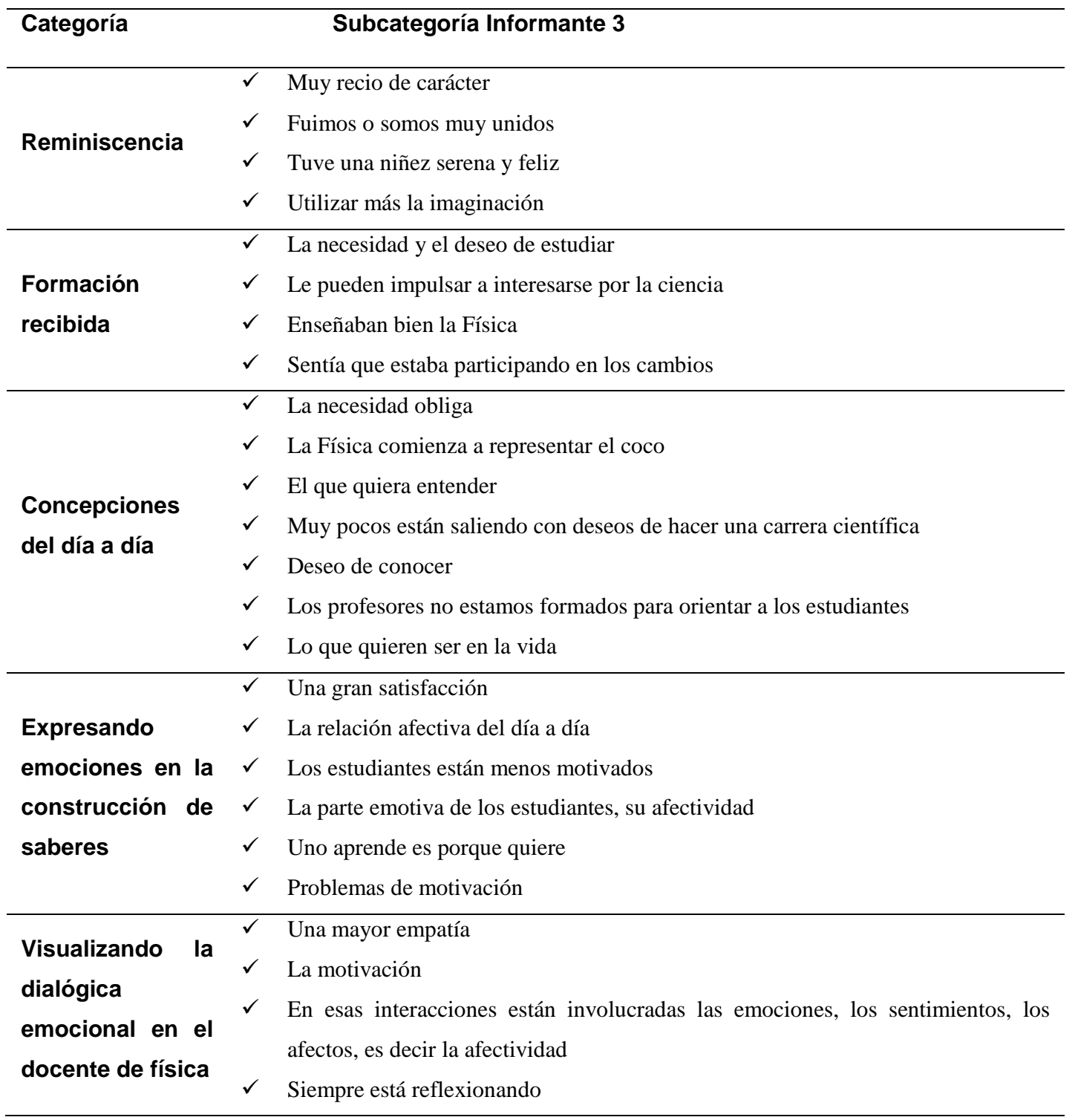


La única satisfacción

$\checkmark$ Revisarse intelectualmente y emocionalmente

\section{Develando la Realidad-Elaboración de la Estructura Teórica Consensuada}

Aquí son presentados los resultados iniciales contrastados surgidos del análisis hermenéutico de la información proporcionada por los actores sociales, quienes contribuyeron a la formación de significados relativos a la dimensión afectividad como docentes de Física en su praxis educativa más allá delo cognitivo. En tal sentido y considerando el amplio espectro de interpretaciones posibles, se muestra lo que emergió del proceso investigativo:

En la categoría reminiscencias se estructuró la descripción de las vivencias de los docentes relacionadas con sus experiencias en el entorno familiar y con sus allegados, se evidenciaron como ejes transversales la afectividad, lo familiar, la recreación y la educación. Surgieron como elementos de convergencia la tranquilidad, lo feliz y lo apacible de sus respectivas infancias, lo que de alguna manera trascendió más allá de esta etapa en cada uno de ellos, incidiendo en la vida futura de la persona como docente, así como en el grupo social de pertenencia.

También surge como factor de convergencia lo importante de compartir y de permanecer unidos ante las vicitudes de la vida. Compartir es una acción que permite a la persona aprender de los demás y a su vez lo hace participé en el acto de dar de sí de enseñar, por lo cual representa un elemento fundamental en la formación de todo ser, ya que quienes hoy se están formando serán, los adultos del mañana de acuerdo a la educación que se les ha proporcionado.

Un elemento que también surge aquí es el que se expresa en el sentir el arraigo y el sentido de pertenencia a un grupo y a una Institución, lo que representa un factor importante en el contexto emotivo de las personas que constituye además una dimensión subjetiva de la cohesión social, es lo que en cierto modo vincula el ser afectivamente a las cosas y a lo que hacen.

Asimismo, se enaltece la empatía de los demás, cuando alguien en los momentos de dificultad está dispuesto a brindar su apoyo y su espíritu de solidaridad a superar las dificultades, sustancialmente las que permiten un mayor conocimiento en un área determinada y tan particular

Tabla 4 Información generada en la triangulación para la Categoría Reminiscencia

\begin{tabular}{lccc}
\hline Reminiscencia & Informante 1 & Informante 2 & Informante 3 \\
& Subcategoría & Subcategoría & Subcategoría \\
\hline
\end{tabular}


RELACult - Revista Latino-Americana de Estudos em Cultura e Sociedade

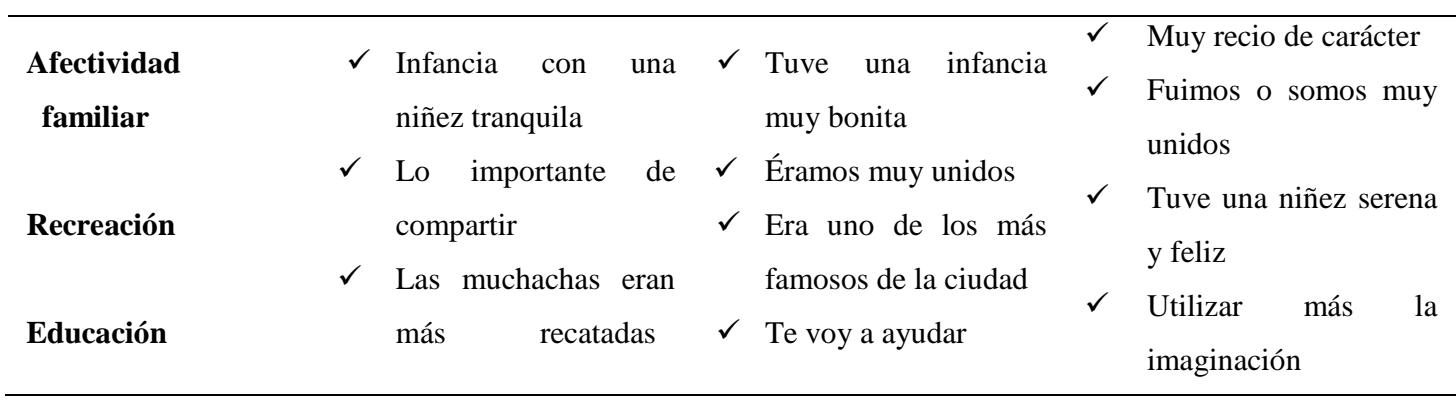

En la categoría formación recibida se estructuró la descripción de las vivencias de los docentes relacionadas con todas sus experiencias personales que contribuyeron con su formación la creación de la red de significados denominada sapiencia de la Física. Se evidenciaron como ejes transversales la educación, los intereses, los hábitos y el legado familiar afectivo. En la conformación de esta categoría se apreció el surgir de la concordancia en relación al elemento que hace mención al sembrar amor por el estudio, el deseo de prepararse para ser mejores personas y alcanzar un bienestar económico superior al que se tenía en esos momentos, ya que los estudios se constituyen en un medio para lograr las metas personales, es decir, que esa motivación representó ulteriormente un proceso que activó la conducta del individuo, hacia una determinada dirección o meta, es decir, constituyó el motor que condujo las acciones hacia el logro de los objetivos y la realización del ser como persona y como docente de Física.

Otro elemento de resaltar correspondió a la estrategia utilizada en la asimilación de los saberes, por una parte, la fuerza del sentimiento, específicamente del amor, la cual induce al ser a superar todas las dificultades, yendo más allá de cualquier lógica, lo hace prevalecer sobre sus limitaciones, induciéndolo a innovar y a recorrer caminos impensados.

Se presenta también el contraste entre elementos incluidos en esta categoría y en la categoría reminiscencias, manifestadas por el progenitor que sostenía una actitud rígida con sus hijos formándolos de manera recia y quien por el contrario los aupaba y los estimulaba en los momentos de dificultad o de fracaso ante las circunstancias y hechos de la vida.

La situación representa dos visiones diferentes en el afrontar ciertos hechos de la vida y que aun cuando produjeron el resultado de formar íntegramente a los actores sociales participantes en la investigación, ponen de manifiesto la necesidad de dosificar de manera adecuada los elementos formativos en la vida del ser, para lograr un desarrollo en el plano afectivo que conduzca a constituir de manera integra a las personas y no existan a posterior situaciones negativas que influyan en su quehacer, derivadas de la influencia de estos elementos. 
RELACult - Revista Latino-Americana de Estudos em Cultura e Sociedade

Tabla 5 Información generada en la triangulación para la categoría formación recibida

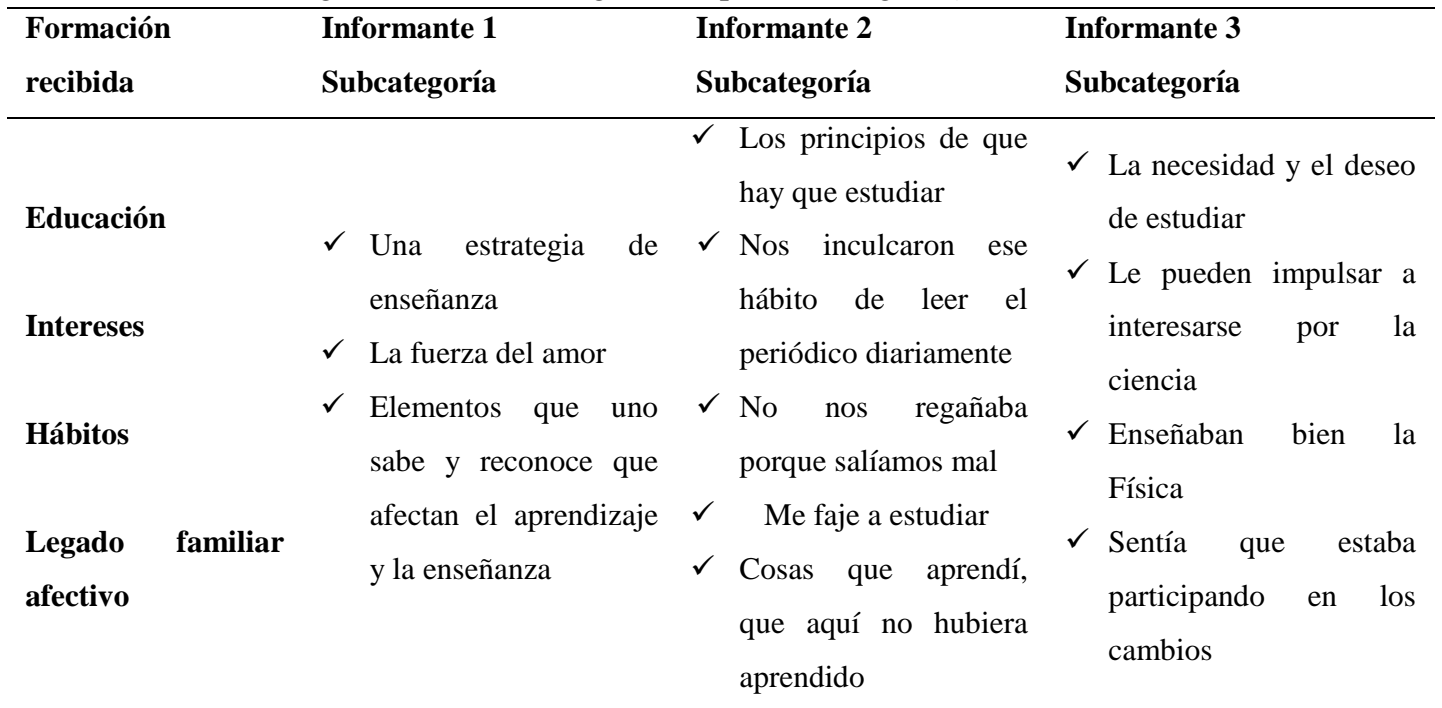

En la categoría Concepciones del día a día se estructuró la descripción de las vivencias de los docentes que involucra todas aquellas acciones y rutinas comportamentales relacionadas con el diario hacer de los actores sociales, donde se manifiesta la capacidad comunicativa de los participantes en el acto de comunicar, para compartir los contenidos culturales y curriculares. Se visualizaron como ejes transversales los deseos, los intereses, las orientaciones y la educación. En la conformación de esta categoría, despunta como elemento de convergencia el gusto y el placer por las actividades inherentes a la Física en su proceso de enseñanza aprendizaje de los diversos contenidos, enfatizándose que el placer de aprender relacionado con el aprendizaje holístico, requiere una serie de condiciones que activan el aprendizaje y suscitan la creatividad, la libertad y la alegría de aprender.

También destaca como elemento surgente el que hace referencia a las dificultades intrínsecas al contenido de la Física, considerándose además que hay siempre un margen de aplazados en la materia por los muchos factores que influyen en ello.

Surge también el elemento que señala a nivel oficial, la no consideración de la importancia que la afectividad tiene en la asimilación de saberes en Física, ya que ninguno de los pensa de la carrera de estudios de Física presenta alguna materia con un contenido que aborde esa inquietud o temática, evidenciándose además la importancia que esa tiene en la relación docente-estudiante.

Tabla 6 Información generada en la triangulación para la categoría concepciones del día a día

\begin{tabular}{|c|c|c|c|}
\hline $\begin{array}{l}\text { Concepciones } \\
\text { del día a día }\end{array}$ & $\begin{array}{l}\text { Informante } 1 \\
\text { Subcategoría }\end{array}$ & $\begin{array}{l}\text { Informante } 2 \\
\text { Subcategoría }\end{array}$ & $\begin{array}{l}\text { Informante } 3 \\
\text { Subcategoría }\end{array}$ \\
\hline Intereses & $\begin{array}{l}\checkmark \text { He logrado estimular } \\
\text { algunos estudiantes } \\
\text { para que participen }\end{array}$ & $\begin{array}{ll}\checkmark & \text { No tenía en mente } \\
\text { otra cosa } \\
\checkmark & \text { Me gustó tanto }\end{array}$ & $\begin{array}{ll}\checkmark & \text { La necesidad obliga } \\
\checkmark & \text { La Física comienza a } \\
& \text { representar el coco }\end{array}$ \\
\hline
\end{tabular}


RELACult - Revista Latino-Americana de Estudos em Cultura e Sociedade

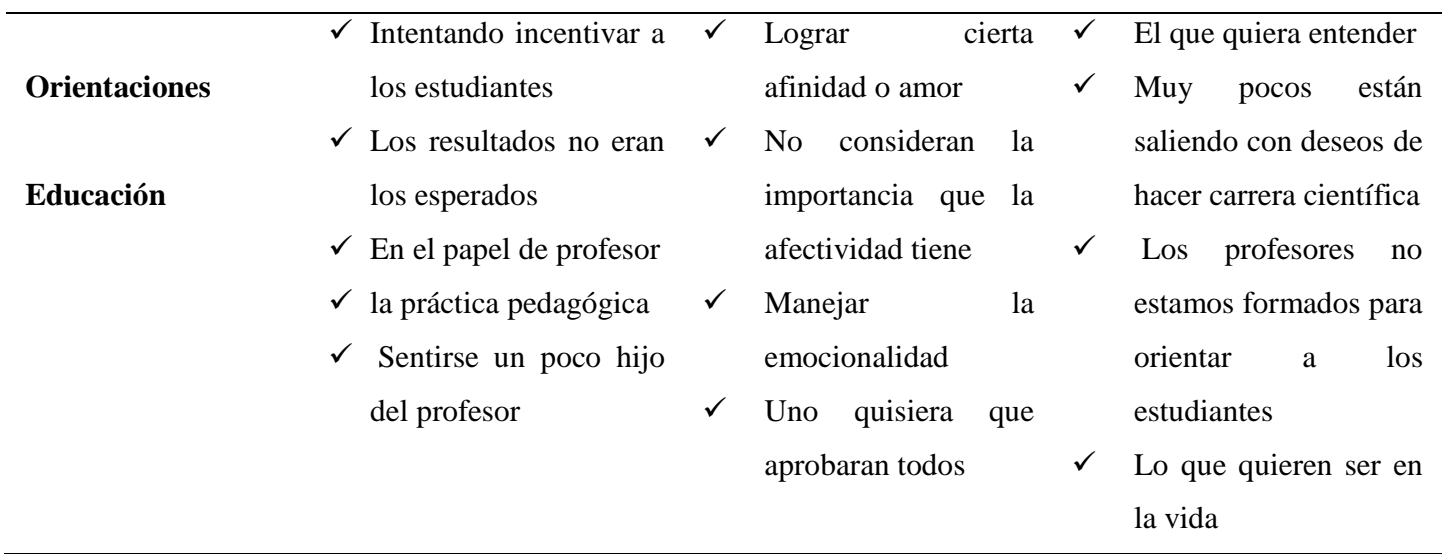

En la categoría Expresando emociones en la construcción de saberes se circunscribe el conjunto de situaciones en las cuales se vieron incluidos los actores sociales que de alguna manera reflejan la expresión de una dimensión afectiva que involucra los sentimientos de los entrevistados en el proceso de construcción de saberes en Física. Se destacaron como ejes transversales la afectividad, los gustos y los sentimientos. En la organización de esta categoría, brota como elemento de afinidad la afectividad, la cual es esencial en todas las manifestaciones del ser humano y se constituye según su incidencia en un estímulo a la motivación al logro en el proceso de asimilación de saberes en Física.

Tabla 7 Información generada en la triangulación para la categoría expresando emociones en la construcción de saberes

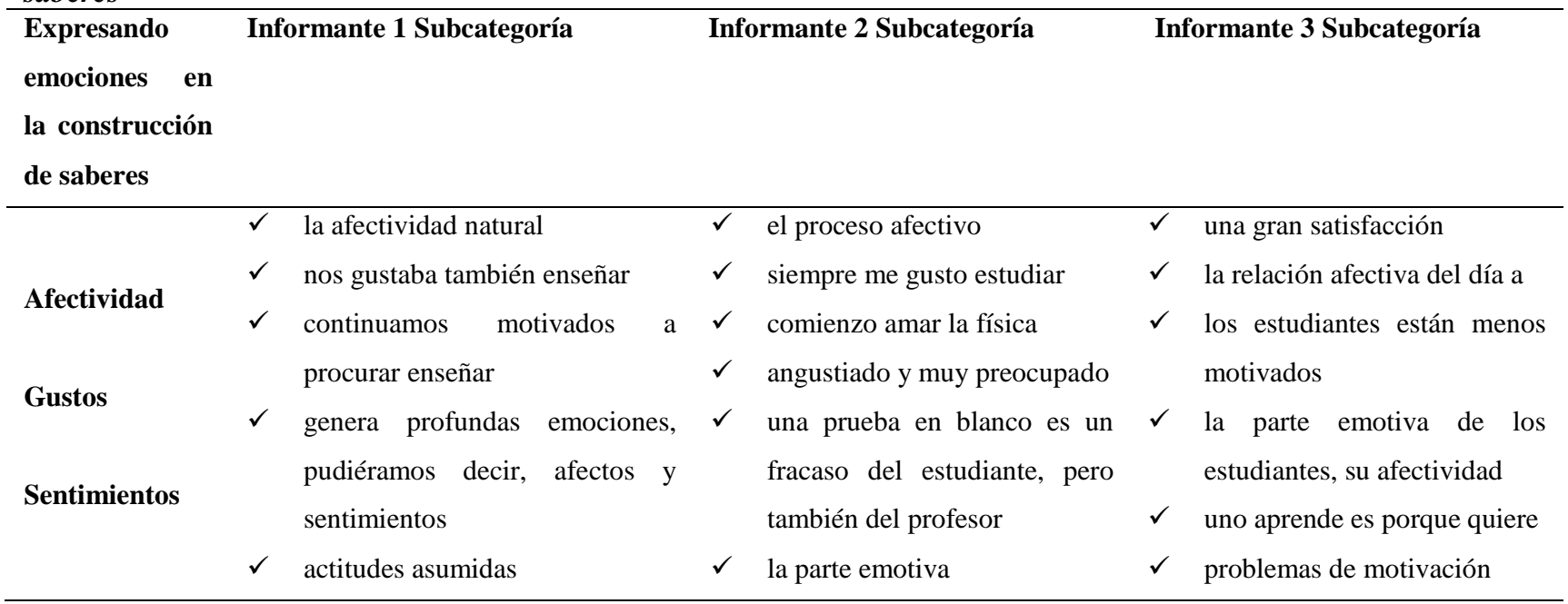

En la categoría Visualizando la dialógica emocional en el docente de física se circunscribe el conjunto de situaciones vivenciadas por los docentes en el desarrollo del acto educativo que involucra el surgir de emociones y que permite visualizar la dialógica afectiva en la dupla docente-estudiante. Se puntualizaron como ejes transversales la motivación, la afectividad, las satisfacciones, el temor y la emotividad. En la sistematización de esta categoría descolló como elemento de concordancia la emotividad, la cual se exalta por lo 
esencial que resulta en la interpretación de la realidad que les circunda y en la asimilación de los saberes, en cuanto esencia de las manifestaciones del ser en su interacción con esa. Además, se considera que un ambiente afectivo es fundamental para la generación de actitudes positivas en el aula porque favorece la capacidad de aprender del estudiante y a su vez el comportamiento como profesional del futuro, ya que todo en la vida son emociones.

También despunta como elemento de coincidencia la dureza con los estudiantes, el generar temor en ellos, mediante un comportamiento rígido y una actitud que no permite congeniar, les produce malestar y distanciamiento del curso, estableciendo de consecuencia una barrera para la asimilación de los saberes, debido a que obstaculiza la participación de los estudiantes en las actividades de clase.

Otro componente que surge como elemento de concurrencia es la motivación, que corresponde a la pasión por la realización, es decir el lograr metas, superar dificultades, resolver problemas y que incluye el compromiso, la iniciativa y el optimismo.

Tabla 8 Información generada en la triangulación para la categoría visualizando la dialógica emocional en el docente de Física.

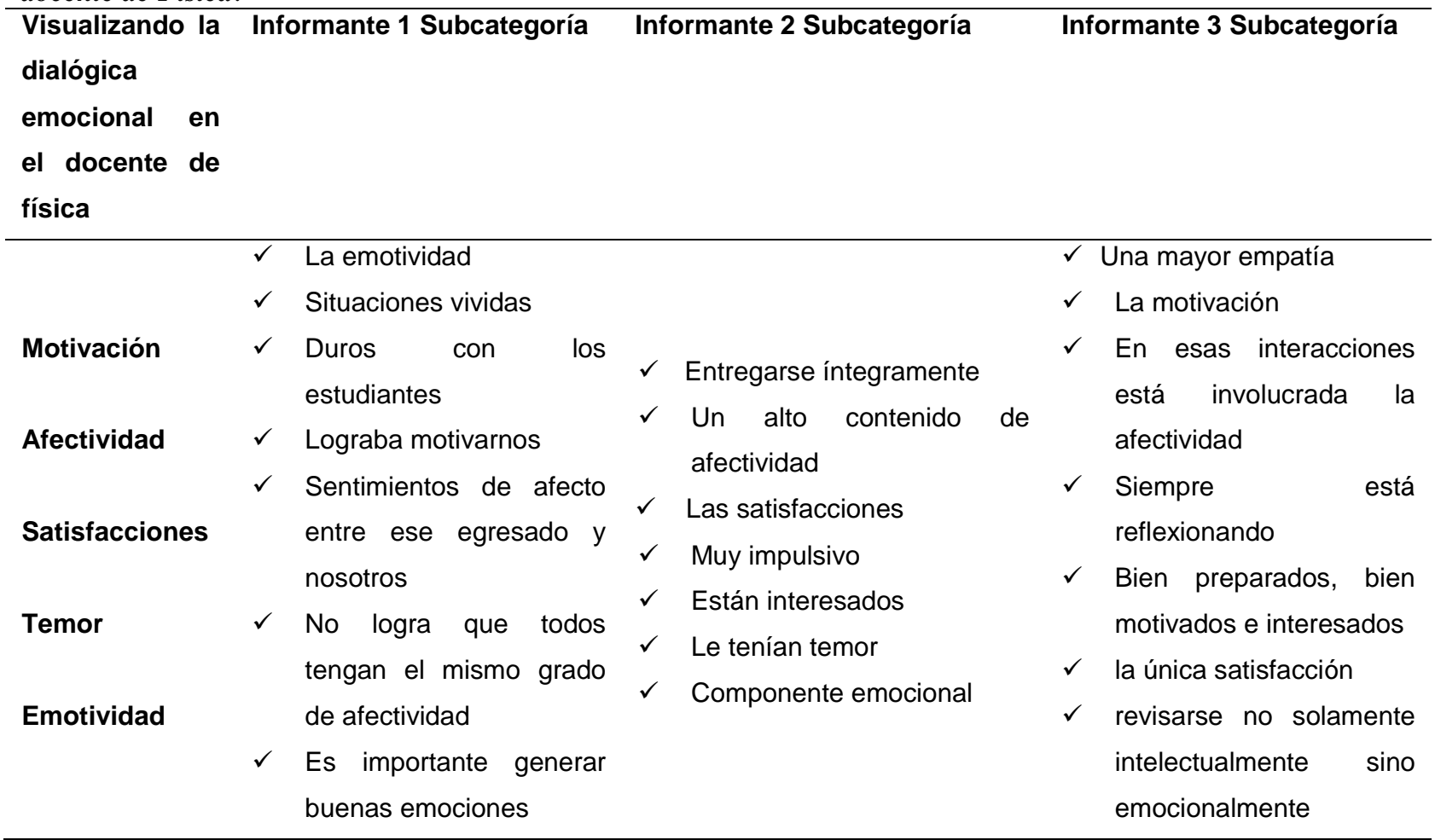

\section{El Discurso Conclusivo}

Orientarse en la intención de la investigación que correspondió al rol de la dimensión afectividad del docente de Física en su praxis educativa, más allá de lo cognitivo, significó apropiarse de la realidad representada por las interacciones en el contexto del aula y fuera de ella, entre el profesor de la especialidad y sus estudiantes, considerando los aspectos 
cognitivos y afectivos involucrados en el acto educativo, apreciados a través de las vivencias de los distintos momentos experimentados desde la perspectiva de los docentes y reconstruidos mediante sus narraciones. Construcción que emergió de la imaginación creativa del investigador haciendo uso de la dialéctica interpretativa, la reflexión, la comparación y la analogía de las distintas situaciones abordadas.

En base a lo considerado, se pudo argumentar que en el caso de la educación concerniente con el proceso del surgimiento y asimilación de saberes en el campo del conocimiento referido previamente, se realizó históricamente una división entre lo racional y el aspecto subjetivo del ser, tanto del estudiante como del docente, representado por el plano afectivo y sus manifestaciones en las respectivas interacciones en el acto educativo, un ejemplo de ello está representado por la frase que se suele decir: deja de lado los sentimientos y utiliza la razón, la inteligencia, esta frase de uso común da idea de la separación que se hizo del componente racional y el afectivo-emocional en el ser humano. Separación que se ha prolongado en el tiempo y permanece aún hoy día de manera más que latente en muchos de quienes se ocupan de conducir el acto educativo.

La situación descrita provocó que la visión que predominó en el proceso enseñanzaaprendizaje de esta ciencia haya conducido hacia un modelo sesgado y parcializado que no solamente ha obviado la esencia misma del ser humano, sus emociones y sentimientos, sino que además ha denigrado de ellos en su praxis, provocando a la larga un distanciamiento de los estudiantes a la hora de seleccionar los cursos inherentes a sus contenidos. Todo esto en cuanto que de acuerdo a la aproximación de la realidad evaluada, los sentimientos son esenciales para el pensamiento, y el pensamiento lo es para los sentimientos, más allá del hecho que en algunos momentos hay predominio de uno sobre el otro. No es posible separar un componente del otro, ya que la persona es una totalidad indivisible, la separación de sus componentes es solo un artificio seccionador a los fines de estudiarlos.

En esta aproximación se aprecia además que en las distintas etapas o momentos del proceso enseñanza aprendizaje afloran interna y externamente una serie de emociones y sentimientos, que pueden movilizar al involucrado (docente o estudiante) a la acción, lo pueden estimular a motivarse, entusiasmarse, alegrarse, apasionarse, lo cual lo mantiene interesado en su actividad induciéndolo a la creatividad, al uso de la imaginación y la innovación; pero, también lo pueden inhibir, desmotivar, estresar, enojar, sentirse triste, conduciéndolo a la apatía y la no participación.

Esto último es lo que ocurre, cuando se establecen patrones clásicos de rigidez y dureza en la relación con los estudiantes en el acto del desarrollo de las actividades en aula y 
fuera de ella, estableciendo el distanciamiento y la frialdad en el trato personal, algo que pasa con frecuencia en el desarrollo de la dinámica de los contenidos que involucran la Física y tiene que ver con carreras de corte fundamentalmente científico, afines a ella o de carácter aplicado que conciernen este campo, como la ingeniería, donde los estudiantes se sienten tratados como unos más del montón, insignificantes, aun cuando tal situación no escapa a Instituciones donde se va aprender a aprender la Física. Ni tampoco escapa a profesores, que por su conocimiento de la materia en cuanto a contenido se refiere, no se tendría nada que objetar, pero que con su trato y el desarrollo de las dinámicas en aula dejan de lado el plano afectivo de sus educandos y el suyo propio, trasformando la actividad pedagógica en algo insípido, sin estímulo a la motivación.

A su vez, al reflexionar sobre el acto educativo en el caso de la Física, el cual es un proceso que permite a los individuos formarse en el campo de las ciencias naturales considerando los aspectos físicos de los cuerpos y de poder hacerse una idea de los distintos fenómenos que ocurren en su entorno. Se aprecia de estas reflexiones sustentadas en lo narrado que en ese proceso de aprendizaje debe ser causa común la motivación, la cual debe estar presente tanto en el docente como en cada uno de los estudiantes, ya que en términos generales representa un proceso que determina, impulsa y desarrolla el comportamiento de los seres humanos en situaciones específicas para satisfacer sus necesidades y superar situaciones de conflicto.

En el campo educativo la motivación hace referencia a factores que inciden en los actores que participan en la acción de educar, en el docente mejorando su calidad del acto, mediante una praxis que considera metodologías constructivas y creativas que estimulan la imaginación, la experimentación y la creativa haciendo uso de las herramientas adecuadas y que orientan un aprendizaje significativo. En el caso de los estudiantes, esa hace referencia a factores que incitan al estudiante a participar de forma activa en la dinámica de la clase, a realizar las distintas actividades propuestas, a investigar, experimentar y aprender de forma creativa y estimulante.

En la actualidad la estimulación a la motivación en el campo del aprendizaje de la Física tiene toda una serie de incentivos, donde el docente a la hora de evaluar no solo toma en cuenta aspectos cognitivos del estudiante, sino que además considera sus habilidades, capacidades, cualidades y actitudes, para lo cual se vale de diversas estrategias y herramientas, todo con la finalidad de despertar su interés y participación activa en el desarrollo de las distintas dinámicas.

Sin embargo sucede que no obstante se realice lo expuesto precedentemente, en 
algunos casos los estudiantes evidencian carecer de una motivación real que satisfaga un deseo interno de estudiar por el placer de aprender, por el gusto o el goce de hacerlo, para comprender la realidad involucrada. Las razones de ello podrían estar vinculadas a problemas con el afecto en la familia y a las condiciones socioeconómicas de su entorno o tal vez en una situación coyuntural generacional que tiene sus raíces en una sociedad postmoderna denominada de la información, donde la vigencia es el todo vale y el predominio del consumismo tiende a reducir al ser humano a un simple objeto de consumo.

Se pudo apreciar además que en el campo de las relaciones afectivas y de cómo ellas influyen en el proceso de enseñar la Física, así como en el de resolver situaciones conflictivas emocionales que surgen en el desarrollo del acto educativo para la asimilación de conceptos y principios que relacionan sus contenidos curriculares, el docente es dejado solo, a la deriva, que se las arregle como pueda por su cuenta. No existiendo un plan o un programa de apoyo Institucional que le permita orientarse para afrontar las situaciones que en relación a esa temática se le pueden presentar.

Se aprecia, además, que ni siquiera en los pensa curriculares de su formación como docente, ni a nivel de pregrado, ni de postgrado; existen materias que aborden tal contenido, lo que indica que al profesor en esta área del conocimiento, no se le prepara, se da por descontado que tal argumento carece de importancia, o bien que las circunstancias dictaran las pautas a seguir. Se hace por tanto necesaria una revisión curricular en esta carrera donde quienes participen reflexionen a fondo sobre esta problemática, aportando la visión participativa en su superación.

Por otra parte, para algunos profesores el plano afectivo-emotivo, no tiene ninguna incidencia en el desarrollo del acto educativo para la asimilación de conceptos y principios de la Física, ya que eso para ellos solo representa pura palabrería, dentro del contexto del contenido de la materia y los argumentos que la sustentan.

En el centro de la situación considerada, está la esencia que los conocimientos de la Física fueron realizados por personas, para ser trasmitidos a otras personas y por tanto cada una de las acciones encaminadas hacia el surgimiento de saberes en este campo del conocimiento, conduce hacia actuaciones racionales o intelectuales y subjetivas las cuales están impregnadas de afectividad por las relaciones de unos con otros y consigo mismo, por el proceso auto reflexivo de cada uno de los participantes; ya que todas las actividades del ser humano llevan implícita una emoción, un sentimiento, un estado de ánimo, o algún rasgo de sensibilidad.

Se debe tener presente que los Profesores de Física son seres humanos, los cuales 
tienen sentimientos y por tanto son emotivos, lo que implica que todo proceso dialógico que los involucra, como el del acto educativo, comprende también su plano afectivo y para poder ser comprendido en toda su dimensión, debe ser considerado más allá de lo cognitivo. Es decir, que el docente de Física en su praxis educativa cotidiana interactúa en un dialogo de emociones.

Agradecimientos. Este trabajo se hizo gracias al aporte del Consejo de Desarrollo Científico, Humanístico, Tecnológico y de las Artes (CDCHTA) de la Universidad de Los Andes a través del financiamiento del proyecto de investigación NURR-H- 600-17-04-AA.

\section{Referencias}

Ausubel, P. (1991). Psicología educativa: un punto de vista cognoscitivo. México. Trillas

Alonso J y Loza M. 2012. Aprendizaje Dialógico. Consultada el 12 de febrero de 2015. Disponible en: ttp://eoepsabi.educa.aragon.es/descargas/H_Recursos/ h_1_Psicol_ Educacion/h_1.2.Aspectos_sociales/1.9.Aprendizaje_dialogico.pdf.

Burbules, N. (1999). El diálogo en la enseñanza: Teoría y práctica. Buenos Aires: Amorrortu Editores.

Briceño J, Rosario J, Rivas Y, Lobo H, Gutiérrez G, Villareal M, Díaz J y Pineda F. 2009. El aprendizaje de fenómenos electromagnéticos mediante una herramienta interactiva. EDUCERE, Nº. 45, abril-junio pp. 501-507. Mérida-Venezuela.

Briceño J, Quevedo E, Aldana D, Rivas Y, Lobo H, Gutiérrez G y Rosario, J. 2011. Dificultades para aprender Física en el marco del proceso educativo actual. Revista ACADEMIA; ISSN 1690-3226, julio-diciembre. Volumen 10 N²0. Trujillo-Venezuela.

Cohén L y Manion L. (1990). Métodos de investigación educativa. Madrid: La Muralla.

Damasio A. 2010. Y el cerebro creo al hombre. Colección Imago Mundi. Traductor Ferran Meler Orti. Mexico: Destino.

Díaz C, Martínez P, Roa I, y Sanhueza, M. (2010). Los docentes en la sociedad actual: sus creencias y cogniciones pedagógicas respecto al proceso didáctico. Polis, vol. 9, n. 25, 421436.

Elboj C y Gómez A. 2009. El Giro Dialógico de las Ciencias Sociales: teorías sociológicas para organizaciones dialógicas. En Puyal, E., Gómez, C.A. \& Sanagustín, M.V. (Coord). Sociología de las organizaciones: una mirada crítica desde la Universidad (51-68). Zaragoza: Egido.

Flecha R. 2006. Aprendizaje Dialógico y Participación Social: Comunidades de aprendizaje. Consultada el 01 de junio de 2013. Disponible en: http://www.cprceuta.es/comun_ aprendizaje/archivos /aprendizaje_Dialogico.pdf.

Freire P. 1996. Pedagogía de la Esperanza. $2^{a}$.Ed. México: Siglo XXI.

Freire P. 1997. Pedagogía de la Autonomía. Brasil: Paz y Tierra.

Foliari R. 2005. Práctica Educativa y Rol Docente. México: Editorial Limusa. 
García B. 2009. Las dimensiones afectivas de la docencia. Revista Digital Universitaria. Volumen 10, Número 11. ISSN: 1067-6079. Consultada el 11 de mayo de 2014. Disponible en http://www.revista.unam.mx/vol.10/num11/art71/art71.pdf.

Glaser, B y Strauss A. 1967. El desarrollo de la teoría fundada: estrategias de la investigación cualitativa. Chicago, Illinois: Aldine.

Gómez, M.; Gironés, N.; Gíl, M.; Catalá, C.; Bacete, S. y Aparicio, I. (2014). Bases Teóricas del Aprendizaje Dialógico. Consultada el 20 de junio 2017. Disponible en http://subami.blogs.uv.es/files/2013/12/Trabajo-Innovaci\%C3\%B3n-grupal.pdf

Habermas J. 1987. Teoría de la acción comunicativa. Tomos I y II Madrid: Taurus.

Levy N. 2000. La sabiduría dé las emociones. Buenos Aires: Plaza y Janes.

Luengo, J. 2011. La Educación como Objeto de Conocimiento. El Concepto de Educación. Consultada el 26 de junio de 2017. Disponible en http://avancelastablas.es/psicologoseducacion/wp-content/uploads/2016/12/1-EducacionConcepto.pdf

Madera, J. 2008. Docentes en la enseñanza de la Física. Consultada en julio 2012. Disponible en:http://www.monografias.com/trabajos29/practicas-laboratorio/practicaslaboratorio. shtm1\#Relacionados.

Maturana H y Bloch S. 1998. Biología del emocionar y alba emoting. Santiago, Chile: Ediciones Dolmen S. A.

Navarro, R. 2011. Didáctica y Currículum para el Desarrollo Profesional Docente. Madrid, España: Editorial DYKINSON, S.L.

Pérez A. 2011. Pedagogía del amor y la ternura. Consultada el 17 de junio de 2013. Disponible en: http://www.cfipj- http://www.cfipj- Carticle\&id=183:pedagogia-del-amor- yla-ternura catid=y3:prensaMtemid-riK.

Pozo, A.; Álvares, J.; Luengo, J. y Otero, E. (2004). Teorías e Instituciones Contemporáneas de Educación. Madrid: Biblioteca Nueva.

Piaget J. 1969. Psicología y pedagogía. Reimpreso en el 2001. España: Editorial Crítica.

Rubia F. 2007. El cerebro nos engaña. España: Editorial Temas de hoy.

Varas I. 2007. Teoría dialógica de la educación. Barquisimeto, Venezuela: Alsurediciones.

Vygotsky L.1978. El desarrollo de los procesos psicológicos superiores. Barcelona, España: Editorial Crítica. 